\title{
Application of Systems Simulation for Predicting and Optimising Energy Requirements for HDF Production
}

\author{
Cristina Maria Luminea, John Donovan, and David Tormey \\ Precision Engineering Materials and Manufacturing Research Centre, Institute of Technology, Sligo, Ireland \\ Correspondence should be addressed to David Tormey; dtormey@itsligo.ie
}

Received 24 October 2014; Accepted 15 December 2014

Academic Editor: Francis T. Edum-Fotwe

Copyright ( 2015 Cristina Maria Luminea et al. This is an open access article distributed under the Creative Commons Attribution License, which permits unrestricted use, distribution, and reproduction in any medium, provided the original work is properly cited.

\begin{abstract}
Even though simulation has been used so far in manufacturing facilities for modelling supply chain management, production management, and business processes, its applications in managing the energy consumption within manufacturing companies represent a new and innovative research domain. This prompted the research undertaken for the work present in this paper. The main focus of this research is to analyse production management in a manufacturing facility and correlate it with the energy consumption. The research initially concentrates on different simulation methodologies and their application in the current manufacturing domain. Literature relating to the correlation of energy consumption with production management has also been reviewed. This review identified very few previous instances where simulation tools were used to predict the energy consumption in a manufacturing facility. This research brings a novel approach to investigating the adaptability of industrial simulation processes and tools for modelling the energy consumption with respect to a variable production output. The end result of this investigation consists of a better understanding of the production system and the energy losses that were captured by the simulation model.
\end{abstract}

\section{Introduction}

The case study company considered for this research project is a high density fibreboard (HDF) manufacturer. This paper will outline the development of a simulation project that will model the energy utilisation along with the production process of the case study company. Modelling the energy consumption with respect to the production output is a relatively new and innovative research domain within industrial process simulation. The majority of automated manufacturing plants consume high amounts of energy and they usually rely on sophisticated data management systems which monitor, record, and control production resources. Unfortunately the majority of these plants have neither the time resources nor skills necessary to analyze and utilise the gathered data to its full extent. The proposed novelty of this research lies in the application of traditional industrial simulation tools for modelling and optimizing raw material processing to include energy consumption for sustainable and cost efficient production of HDF units.
Research on energy consumption within the manufacturing sector has experienced significant growth in recent years due to high energy costs and its impact on the environment $[1,2]$. Modelling this energy consumption can provide an understanding of how efficiently this energy is being used and identify areas for optimisation. Duflou et al. [3] report that industrial usage contributes to $51 \%$ of the total global energy consumption. This industrial consumption can be further broken down and it has been estimated that, in 2002, manufacturing activities were responsible for $84 \%$ of US energy-related industry $\mathrm{CO}_{2}$ emissions and $90 \%$ of US industrial energy consumption [4]. In the UK in 2013, industrial energy consumption accounted for $16 \%$ of the total energy consumption. However this energy consumption was $51 \%$ lower than it was in 1970 [5]. This reduction has been driven by efficiency gains and changes in the structural nature of the industrial sector, such as the reduction in iron and steel industries. Significant energy savings can be made if one can simulate and model the energy consumption within the industrial process. Gontarz et al. [6] report that the EU estimates an energy saving and energy efficiency 
potential in the manufacturing sector between $13 \%$ and $29 \%$. These potential savings have been backed up by a number of case studies such as Diaz-Elsayed et al. [7], where a discrete event simulation model was used to evaluate different strategies, including energy consumption, and resulted in $10.8 \%$ reduction in production costs. Diaz and Dornfeld [8] reported on the use of a discrete event simulation model to reduce the energy consumption by $8.5 \%$ in a flexible manufacture system. Discrete event simulation is one of the most commonly used techniques for analysing the dynamics of a manufacturing system [9] and a number of papers have specifically focused on its use in the simulation of energy consumption within the manufacturing sector $[1,10,11]$. Thiede et al. [2] report that environmental aspects are not currently considered as standard functions within existing discrete event simulation software.

Li and Pang [12] present findings from their work on the modelling of energy demand in an MDF plant, Carvalho et al. [13] also present work on modelling energy utilisation required for the hot pressing of MDF. Jingge et al. [14] from the University of Canterbury developed a computer model to quantify the energy demand in an MDF plant based on the commercial production process from wood chip preparation, refining, fibre drying, mat forming, and batch pressing to product finishing. The model was validated using plant data which demonstrated it was able to predict energy demand within a discrepancy of $-5 \%$ to $7 \%$ for thermal energy and $\pm 4 \%$ for electricity. Jingge et al. [14] state that according to their knowledge "there has not been any energy demand models published for a commercial MDF plant." These studies demonstrate the effective use of simulation in predicting the energy demand and consumption in medium density fiberboard production facilities, which would be analogous to $\mathrm{HDF}$ production processes, by looking at production management modelling.

The primary focus of the research presented in this paper was to model the case company's production processes with a view to improving overall production and energy efficiency. The manufacturing process of the case company includes two main production lines and a finish line, which, combined, requires $85 \%$ of the company's energy needs. Testing and implementing proposed production and energy efficiency scenarios on physical line setups can be costly and in most instances just not feasible. Through developing simulation models that are representative of the actual production processes, the case company was able to conduct a research on a wide range of production and energy efficiency scenarios without having to impact on any physical production process. Defining and testing multiple production and energy consumption scenarios through the developed simulation models enabled the company's production engineers to be better positioned to determine optimal production systems parameters for increased production and energy efficiencies.

\section{Research Methodology}

The research methodology developed by the authors within this study is adapted from [15] and is summarised as follows.

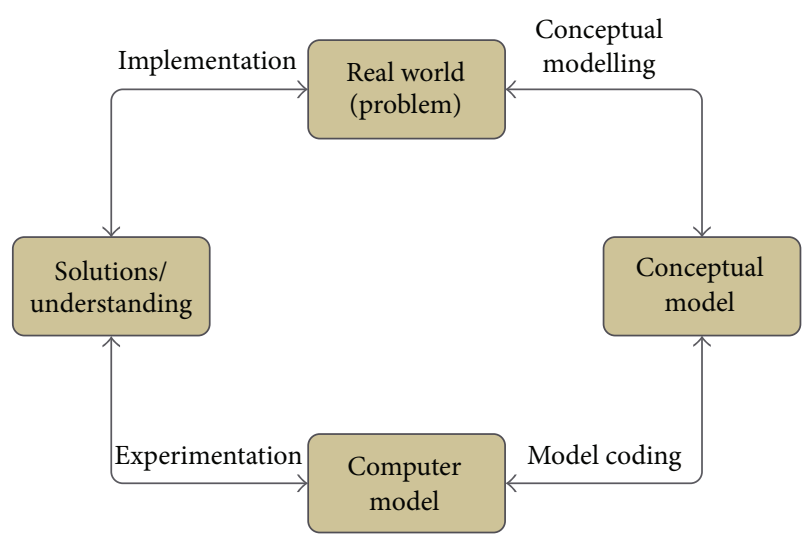

FIGURE 1: The key stages and processes of simulation studies [15].

(i) An investigation into production management and energy consumption within the case company with respect to establishing the correlation between the production volume output and energy consumed by production processes. This involved analysing the layout and workflow of the company's production lines, in addition to conducting quantitative analysis of production and energy utilisation data from the Company's PI and eSight systems used for production and energy monitoring on site. Qualitative research interviews were conducted on site with processes engineers, production managers, planners, and line technicians to establish and validate baseline production data. These interviews also informed the production scenarios that were ran on the completed simulation model in addition to informing the validation of the data and results generated from the models.

(ii) A review of computer simulation tools and their applications was completed as part of this research. The objective of the review was to select the most appropriate simulation tool for modelling the HDF production processes for this research project. The review also gained an understanding of the concept of simulation, its advantages, and limitations through technical and case study reviews. A number of different simulation tools were reviewed for this research project. The outcome of this review process is summarised and presented in this paper.

(iii) A literature review of relevant journal articles addressed the problem of correlating the energy consumption to the production management by using simulation in a similar manufacturing environment.

(iv) Execution of the simulation process: this included the development of the conceptual model, data collection and analysis, model coding, validation of the model, simulation run, scenario implementation, and the analysis of the output results. Figure 1 shows the key stages and processes of a simulation model. 
According to Robinson [15] "the boxes are the key stages in a study and represent the important deliverables":

(i) a conceptual model which represents a description of the model to be developed,

(ii) a computer model which represents the simulation model developed on a computer,

(iii) the solutions and/or understanding which comes about as a result of the experimentation,

(iv) an improvement in the real world which will be obtained from the implementation of the solutions and/or understanding gained, while Robinson [15] considers the arrows to be the processes that enable the movement between the four stages,

(v) conceptual modelling which represents understanding of the problem, determining the modelling objectives, the inputs, the outputs, the model content, and collection of and analysis of the data that is required to develop the model,

(vi) model coding that converts the conceptual model into a computer model,

(vii) experimentation represents the implementation of scenarios in order to obtain a better understanding of the real world and to find solutions to the real world problems, with this phase representing a cyclical process that makes changes to the model's inputs, running the model, inspecting the results, learning from the results, making changes to the model, and so on (Figure 2),

(viii) implementation that according to Robinson [15] can mean implementing the findings of the simulation model in the real world or implementing the learning that can help in future decision making.

\section{HDF/MDF Production}

In his paper, "The Family of Wood Composite Materials," Maloney [16] defines wood composites as being "materials that have the commonality of being glued or bonded together." $\mathrm{He}$ also considers composites to include panels, molded products, lumbers, large timbers, components, and products made through the combination of wood with other materials. In the same article Maloney [16] groups plywood, variations of structural panels, and glued laminated timber under the name of engineered wood products (EWP). Later, particleboard and medium density fibreboard (MDF) have also been described as being engineered wood products. Maloney [16] defines medium density fibreboard (MDF) as " $a d r y$ formed panel product manufactured from lignocellulosic fibres combined with a synthetic resin or other suitable binder." $\mathrm{He}$ also states that MDF production originated in Deposit, New York, in 1966. At the same time he acknowledges previous work that considers the first MDF was manufactured in a plant in Oakridge, Oregon, or in Meridian, Mississippi. As stated above, the base of the MDF production remains the softwood. A diagram of the MDF production process is presented in Figure 3.

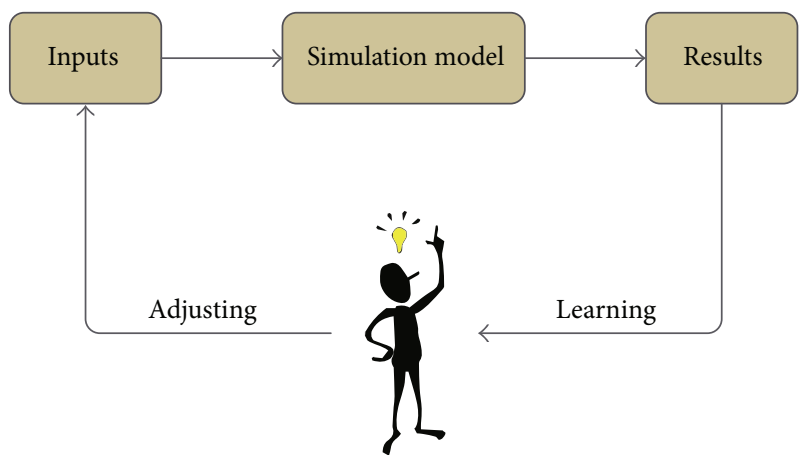

FIgURE 2: The experimentation stage of simulation [15].

The production process of an MDF manufacturing company, as described by Li and Pang [12], starts with the logs of soft wood. These are first chipped and then transported to the manufacturing plant where they are stored in the chip yard. They are then washed and fed to a hopper. In the hopper they are heated using low pressure steam and then they are fed into the preheater or the digester where saturated steam further heats and softens the chips. These are then fed to a refiner which breaks them down into wood fibres at $180^{\circ} \mathrm{C}$. At the refiner entrance a small quantity of paraffin wax is added as moisture repellent. The next step in the manufacturing process is the injection of resin solution when the fibres reach the blowline. From here they are directed into a tube drier where they are dried to a target moisture content of $10-12 \%$. The dried fibres are then directed to storage bins before they are sent to the vacuum forming station for mat formation. A continuous cold press then reduces the mat's thickness, before being cut to size and compressed into a batch press. After the hot pressing the panels are cooled into a star drier and then stored for a few days before sanding, trimming, and cutting into market sizes for packaging.

\section{Developing the Simulation Model}

4.1. Conceptual Model. The first step in defining the conceptual model is defining the research problem. The case company is a HDF manufacturing company and it is one of the largest energy consumers in its located country. The production process, which consists of two main production lines (Line 1 and Line 2) and the finish Line, accounts for over $80 \%$ of its total energy consumption within the Plant. The main problem for the company, which also forms the problem definition for the presented research is that the energy consumption for the production plant has remained constant despite a drop in their production demand. The problem definition for the research presented in this paper is addressed through the optimisation of production processes for more efficient energy utilisation. The novelty of this research is the in modelling of energy utilisation of production processes using traditional industrial simulation tools that can correlate production output to an energy unit input. Having identified the problem, the next step is to determine the modelling objectives. The main objective is to 


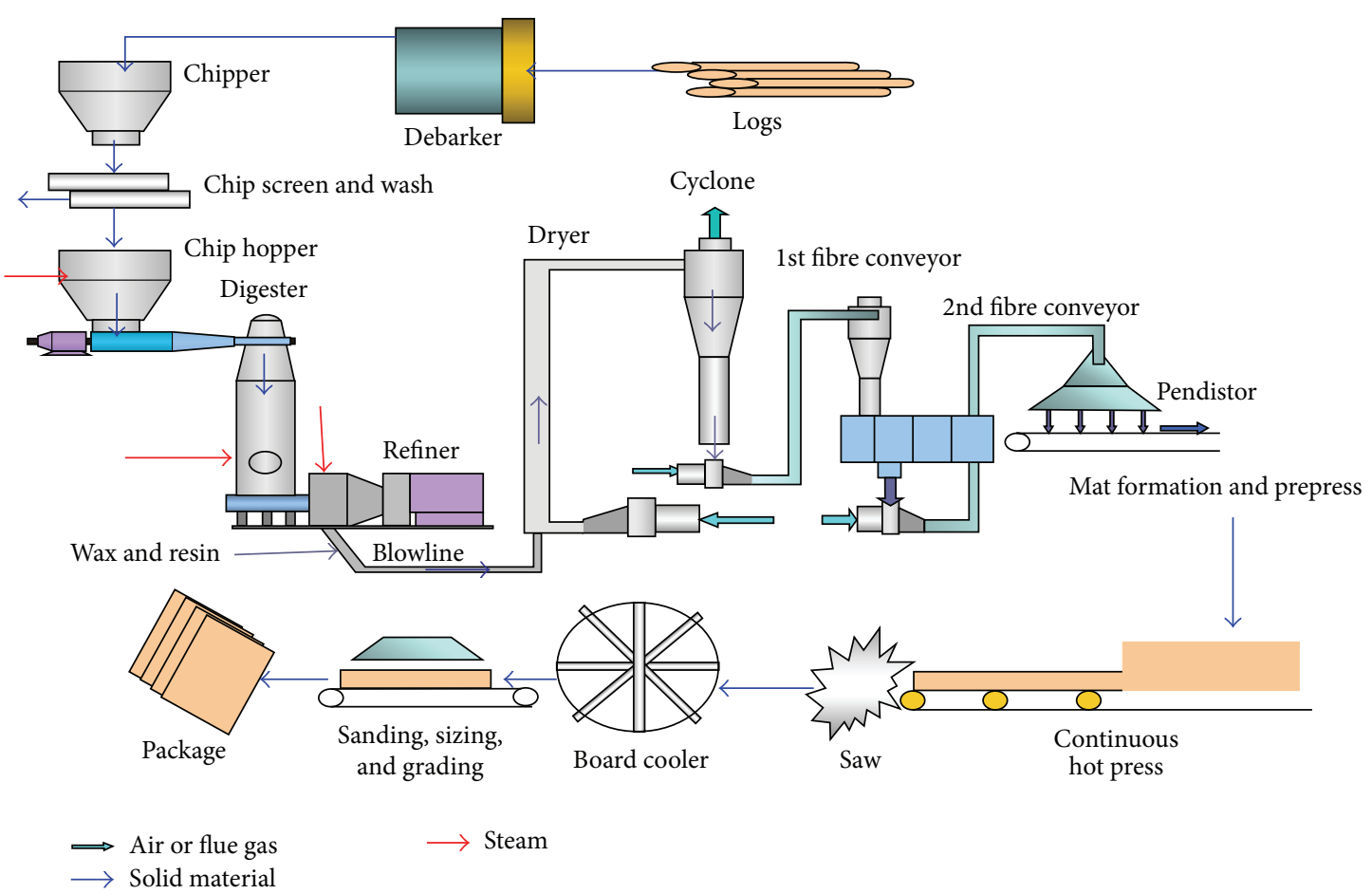

FIgURE 3: HDF/MDF production process: Li and Pang [12].

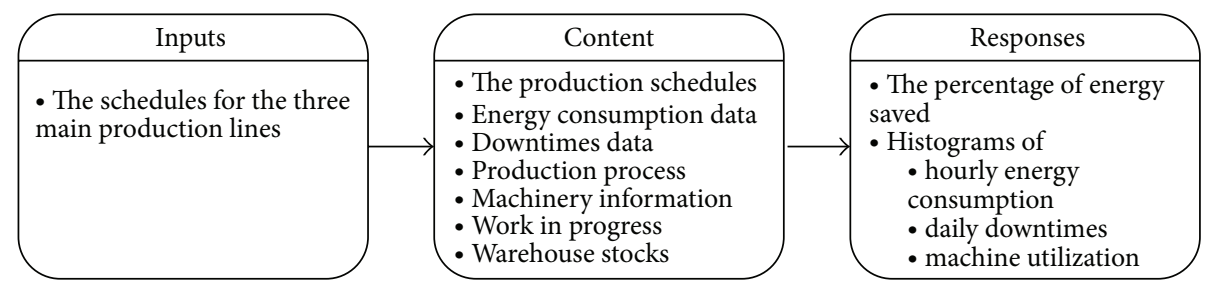

FIGURE 4: Conceptual model.

lower the energy consumption, more specifically, and lower the number of kilowatts consumed per every HDF Unit produced. One of the major constraints of this research is the fact that the three lines are automated and are part of a continuous process, which makes it difficult to alter their layout. That is why the focus of the research is directed at the production schedule. Therefore the main objective is to reduce energy consumption by improving production management through the validation of more optimal production schedules scenarios. Production constraints include the case company order lead-time, which is two weeks. This means that the company has to be able to predict some of the orders coming in and they cannot stop production for more than 4 days. With the problem and the objectives defined the next stage is to design the conceptual model that starts with the inputs and outputs. These are described as the experimental factors and the responses. A diagram of the conceptual model can be found in Figure 4.

The key system inputs are encapsulated in the production schedules for the three main production lines. These production schedules contain key input data about the 3 production lines such as energy consumption in Kw/Hrs, downtime, production process, WIP, and inventory levels.

The response in terms of defining the achievement of the objective (system output) will be the percentage of saved energy, which translates into the amount of money being saved. In terms of identifying the reasons to meet the objectives, the responses will be presented under the form of histograms of hourly energy consumption, of daily downtimes, and of machine utilization. Having identified the model's inputs and outputs, the authors proceeded to identify the content of the model itself. The first issue the authors recognized was that the model needs to be able to accept the experimental factors and to provide the required responses. Therefore the model must be able to represent the schedules for the three main production lines and to provide the relevant reports: the hourly energy consumption, the daily downtimes, and the machine utilization. The model also needs to include the production process along with information on the conveyors, the downtimes, the energy consumption data, the work in progress, and the warehouse stock information. 
TABLE 1: Criteria for the evaluation of simulation software packages.

\begin{tabular}{|c|c|}
\hline $\begin{array}{l}\text { Criteria for assessing the simulation } \\
\text { software }\end{array}$ & Features for assessing the simulation software \\
\hline General features & $\begin{array}{l}\text { System requirements: RAM, operating system } \\
\text { Costs: license, software installation, and training }\end{array}$ \\
\hline Data input/output criteria & $\begin{array}{l}\text { Data importing: electronic spread sheets, AutoCAD files } \\
\text { Input data mode: batch, interactive, } \\
\text { Reports: standard, customized, data statistics generation } \\
\text { Printing: screen layout, generated reports }\end{array}$ \\
\hline Development criteria & $\begin{array}{l}\text { Icons: standard and user-defined library, icon editor } \\
\text { Background chart: image import, screen layout editor } \\
\text { Codification: codification assistants, programming using supplier's language, global } \\
\text { variables, and entity attributes } \\
\text { Typical objects for model development: material handling, grouping, and separation of } \\
\text { entities, schedule, resources, entities arrival, downtimes, and conditional routing } \\
\text { Animation: enable/disable configuration, speed control } \\
\text { date/hour visualization, instantaneous variable, and charts }\end{array}$ \\
\hline Efficiency and testing criteria & $\begin{array}{l}\text { Error detection: execution tracking, inserting stop points } \\
\text { Inspection of instantaneous variables, stepwise execution } \\
\text { Model construct/constraints/validation. }\end{array}$ \\
\hline Execution criteria & $\begin{array}{l}\text { Multiple replications } \\
\text { Batch mode } \\
\text { Warm-up period }\end{array}$ \\
\hline $\begin{array}{l}\text { Technical support/modelling assistance } \\
\text { criteria }\end{array}$ & $\begin{array}{l}\text { Technical user support: user's manual, tutorials application-based examples, on-line help, } \\
\text { technical support, trainings, and software updates. }\end{array}$ \\
\hline
\end{tabular}

4.2. Simulation Tool Selection. Tewoldeberhan et al. [17] describe a methodology for performing an evaluation of discrete-event simulation packages. The authors acknowledge in their paper that the cost and the time involved in the process of evaluation and selection of a simulation software package can be considerable, unless an efficient selection methodology is used. The methodology applied for selecting the most appropriate simulation tool for the research work presented in this paper was structured in 2 phases. The first phase includes the selection of simulation software tools based on a number of specific criteria and related features for assessing simulation software tools. The simulation tools that satisfy features identified from the first phase will be advanced to the second phase where they will be ranked and comparatively evaluated against each other in respect of criteria of importance to our specific modelling requirements. The list of specific criteria and related features for critiquing simulation tools is presented in Table 1.

In order to evaluate simulation software packages on the market, according to these criteria, the authors have used two simulation software surveys published by Swain $[18,19]$. Swain's 2009 survey is the ninth biannual survey of simulation software. Both the 2007 and the 2009 Swain surveys include 48 products, making them one of the most comprehensive surveys completed. Applying the general criteria categories as outlined in Table 1 in addition to the simulation context and constraints established from the concept model, the majority of simulation tools listed in the Swain surveys were discounted. The authors were able to reduce the list of potential suitable simulations tools for this research project down to 10, which included @Risk, Arena, Any Logic, Decision Tools Suite, Micro Saint Sharp, Proof, ProModel, Simcad, Simio, and Vanguard. All of these simulation packages address manufacturing and to a certain degree energy modelling requirements.

Out of the initial 10 simulation tools identified, the authors filtered the list down further to three simulation tools which would be suitable for the project's research modelling requirements: Process Model, Arena, and ProModel. The other packages were disregarded as they did not allow model building using programming or access to programmed modules (e.g., Proof), no input distribution fitting (e.g., Micro Saint Sharp), no code reuse like objects or templates (e.g., Decision Tools Suite), very expensive, even for an academic license (e.g., Any Logic), no optimisation algorithms (e.g., Simio), and no real time viewing (e.g., Vanguard).

Phase 2 of the selection process involved ranking each of the 3 identified simulations with respect to fulfilling essential criteria. The most important criteria considered essential were coding and visual aspects, technical support or modelling assistance, efficiency, the execution criteria or experimentation, testability, and Input/Output criteria. Weightings were applied to the different criteria, with each of the 3 simulation tools awarded a numerical score in order of importance for each criterion and associated features.

Table 2 is a summary representation of the comparative analysis between ProModel, ProcessModel, and Arena that were assessed based on essential modelling criteria for this project.

Table 2 indicates that ProModel scored relatively higher across all criteria than the other 2 simulation tools, Arena and ProcessModel, ProcessModel lost points in terms of visual aspects, which are very important to this project from a presentation and icon customization point of view. ProModel 
TABLE 2: Criteria ranking of simulation tools.

\begin{tabular}{lccc}
\hline Criteria & Arena & ProModel & Process model \\
\hline Coding and visual aspects & 18 & 18 & 16 \\
Modelling assistance & 10 & 10 & 8 \\
Efficiency & 8 & 8 & 7 \\
Experimentation & 6 & 6 & 5 \\
Testability & 7 & 7 & 7 \\
Input/output & 5 & 7 & 7 \\
Total & $\mathbf{5 4}$ & $\mathbf{5 6}$ & $\mathbf{5 0}$ \\
\hline
\end{tabular}

and Arena have better modelling assistance capability when compared with ProcessModel. They also scored better for efficiency and experimentation criteria. From the testability point of view all of the simulation models scored the same, however, for the Input/Output criteria, ProModel and Process Model 7 points, while Arena only scored 5 points. Arena lost points in data statistics generation and the verification of data consistency, which are two important parts in the validation and data analysis processes. Based on the outcome of the selection methodology that was applied, the authors considered the ProModel simulation tool as the most appropriate in respect of the modelling and simulation features required for the research project.

4.3. Data Collection and Analysis. The conceptual model presented above needed to be complemented with real data in order for the simulation model to have a solid base and be credible. From this point of view data collection is the most difficult and important part of the simulation model building process. Most of the simulation models run but the quality of the output data is heavily dependent on the quality of the input data. The type of data needed to be collected is usually dictated by the objectives of a project. In the case of this research project the input data includes but is not limited to production schedule, conveyor speeds, and length and historical energy data. This data was collected from the two monitoring systems available on the site.

"PI," developed by OSIsoft [20], is one of the data collection systems installed in the case company. It is an operational event and real-time data management infrastructure, which brings together all the different types of data from a variety of sources like systems, equipment, solutions, applications, locations, networks, and suppliers. PI gathers and archives large volumes of data on servers. It converts the real time data into actionable information, offering access to real time or historical data for the entire enterprise at any time. It notifies people anywhere from plant to boardroom and it allows for anyone to view the data graphically, to identify problems, and to take corrective actions.

The second monitoring system used by the case company is an energy monitoring system called "eSight" [21]. This is an intranet solution that provides energy reporting and analysis of demand and consumption. It enables the user to monitor standard utilities such as electricity, gas, and water. It also facilitates the presentation of data to be presented in a wide range of graphs, tables, reports, and exports. In addition, reports may be run on an ad hoc basis, saved as templates for later use or scheduled for automatic production and distribution by email. Reports can also be configured to monitor contracts, available capacity, and maximum demand. Since much of the raw data collected from the systems described above cannot be inserted into a simulation model directly, some input analyses such as probability distribution analysis were performed. All the data that was collected over the period of one month was analysed and recorded in an Excel document called "Interface.xls." A graphical representation of all the spreadsheets of this document can be found in Figure 5. This shows the connections between each sheet and the selected simulation tool (ProModel) [22] situated in the middle, as well as the connection between the spreadsheets themselves. The Interface document template also replicates the look and feel of most of the documents currently generated in the company. From this point the data is imported into the simulation model and used to predict stocks and energy consumption as well as performing various scenarios with the purpose of lowering the energy consumption. The data generated by the model is then exported in the "Results" excel document. This will contain general results on production and energy consumption.

4.4. Simulation Model Build and Execution. The authors started to build the simulation model by mapping the three main production lines. You can find a screenshot of the ProModel simulation model in Figure 6. After defining the locations the authors proceeded in defining the entities of the simulation model representative of the wood fibre, the panels, and the skins. For the purpose of modelling the energy consumption, the production schedules, and the production downtimes a control entity has also been defined. As an example, in the case of energy consumption, the control entity cycles inside the location every hour, determining the times at which energy consumption needs to be recorded.

The next step in the simulation model development consisted of the definition of the processes that the entities need to follow within the system. This resulted in a basic representation of the production process of the case study company, which was followed by the implementation of the production schedules. The data representing the three production schedules for the three main production lines was imported from the excel interface document spreadsheet. The control entity created in Figure 6 is used to determine each day's production schedule by cycling inside each location at an interval of 24 hours. After the implementation of the production schedule for the three production lines, the authors proceeded in the implementation of the production downtimes and the energy consumption. This part of the model uses the distributions created from the raw data gathered in the case study company. In terms of the energy consumption, the model records the data every hour. For the data to reflect the reality, the model samples three different user distributions depending on the schedule of the production line.

The final part in the model coding was the implementation of the work in progress and the warehouse stock. During 


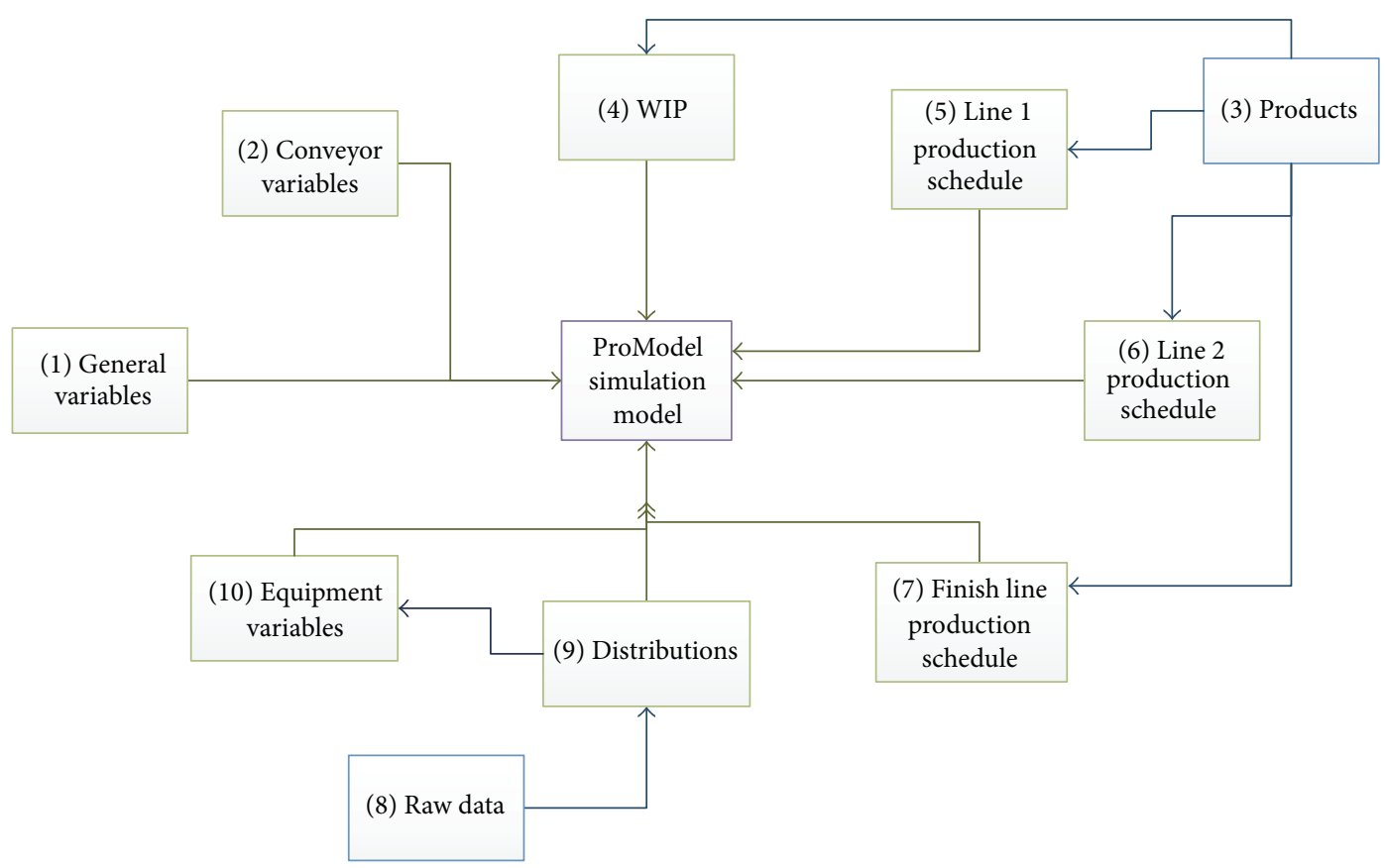

FIGURE 5: The interface document template.

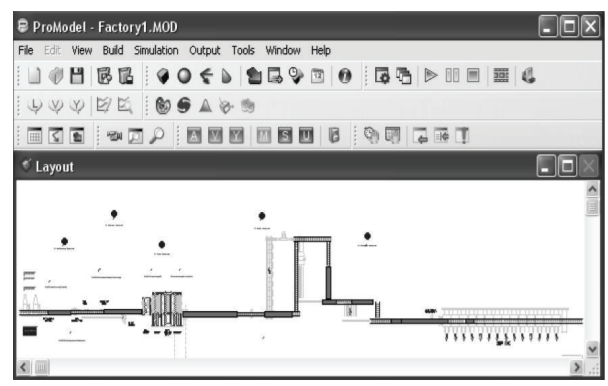

Figure 6: The ProModel model of the case study company.

the simulation run, the model is populating seven different arrays with results of the daily production, hourly energy consumption, and work in progress as well as warehouse stock and demand.

All of these results are exported in the Results.xlsx file where, for a better understanding of them, reports, charts, and diagrams are being created.

\section{Model Validation and Scenario Implementation}

5.1. Model Runtime. The results of the simulation are exported into the Results.xls $x$ document. A graphical representation of this document can be found in Figure 7. All the data recorded in this document is used for analysis through charts and diagrams. The simulation model is run 5 times in order to improve its accuracy therefore requiring 5 sets of corresponding excel spreadsheets, each set containing the following sheets: Line 1 Results, Line 2 Results, Finish Line
Results, Overall Results, Stock Levels, Line 1 Energy, Line 2 Energy, and Finish Line Energy.

Line 1 Results, Line 2 Results, and Finish Line Results contain the production schedules for the three production lines. These include the day of the month, the run schedule for each day, the planned production, and the production resulted from the simulation model.

The overall results page records the total amount of HDF Units produced by each of the two main production lines and the total amount of HDF Unit cut by the finish line. The stock levels spreadsheet records the amount of HDF Units available in the work in process area (WIP) and the warehouse, before and after the simulation run.

This sheet is meant to assist the case study company to predict the types of HDF Units they need to produce according to their demand. The final three sheets Line 1 Energy, Line 2 Energy, and Finish Line Energy record energy consumption throughout the simulation run. Both Line 1 and Line 2 record eleven values each for every hour within the simulation run while Finish Line records five values for every hour within the simulation run. All of these values form data streams corresponding to the energy meters that monitor the production process. After the data is exported in the corresponding excel spreadsheets, it can be analysed with the help of graphs and charts. An example of the Finish Line energy consumption graph throughout a month can be found in Figure 8.

The horizontal axis represents the days of the month while the vertical axis records the amount of energy in kilowatts per hour consumed. The five streams of data that can be observed through this graph represent energy consumption recorded by five energy meters in the production process that monitor the energy consumed within the Finish Line: 


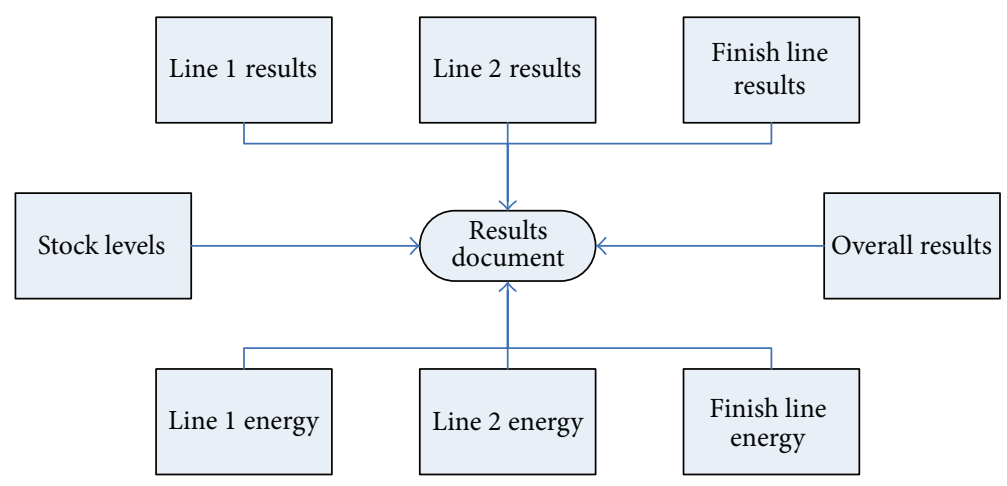

FIGURE 7: Graphical representation of the results document.

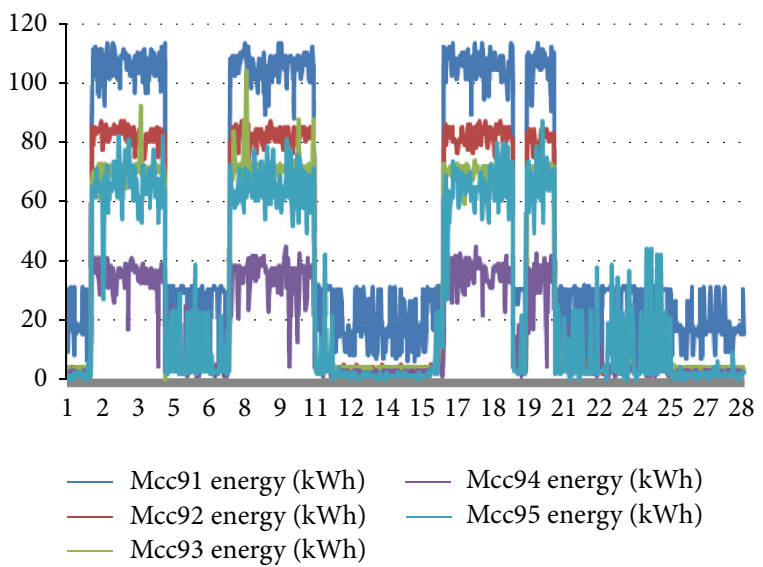

FIgURE 8: The Finish Line energy consumption throughout one month.

MCC91, MCC92, MCC93, MCC94, and MCC95. Each of these meters records the energy consumed by different parts of the production line. From Figure 8 the times can be observed when the line was running and when it was in shift cycle downtime. Looking at the graph at a larger scale one can also observe the downtimes in the line and the part of the line that corresponds to these downtimes. Further analysis can allow production engineers to avoid certain unpredicted events, if the simulation is being run on a longer period of time. As an example they may notice the repeated or prolonged occurrence of certain downtimes within the energy consumption recorded by a certain meter. This could give them enough time to investigate that specific part of the production line and prevent the downtime from happening. Another way of looking at the data exported by the simulation model shows that out of the three production lines Finish Line consumes the least amount of energy per month while Line 1 and Line 2 are the main consumers with roughly the same amount of energy consumed per month. This can be noticed in Figure 9 which looks at the energy results within a month of simulation run. The horizontal axis records the days of the month while the vertical axis presents the amount of energy in kWh consumed. The three streams of data that are being graphed represent the total energy consumed by

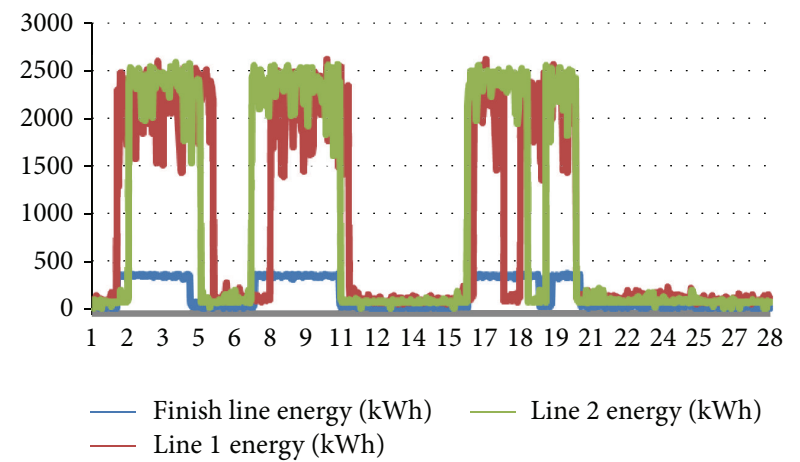

FIGURE 9: The total energy consumption for the three production lines.

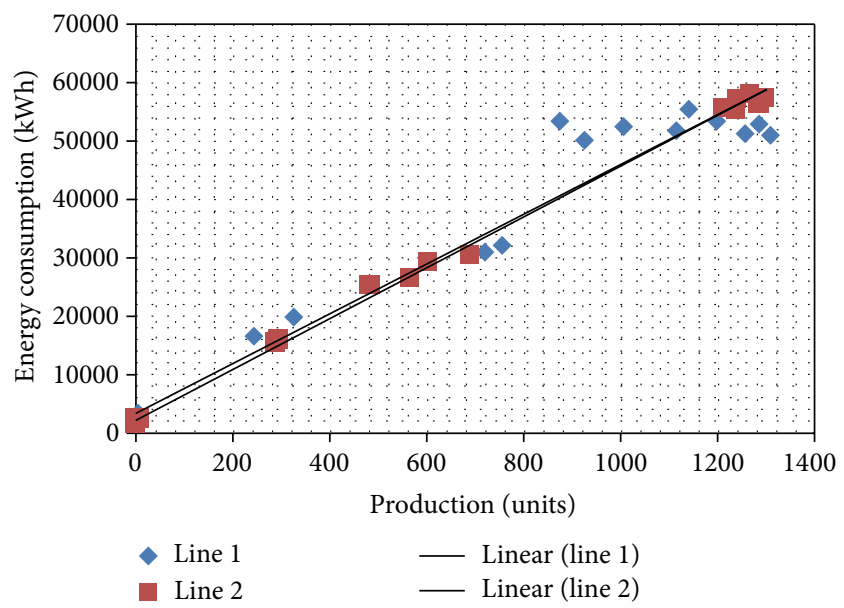

FIgURE 10: The correlation between production and energy consumption for Line 1 and Line 2 .

each production line, recorded on an hourly basis within the simulation run.

In addition to energy consumption, the simulation model also exports data related to production for each of the three lines. These two sets of data can be helpful in understanding the correlation between energy consumption and production. Figure 10 shows this correlation for the two main production 
lines: Line 1 and Line 2 . The Finish Line is not presented on the same graph here because of the significant difference in both the energy it consumes and its production levels compared to the other two lines. From Figure 10 it can be observed again that the two main production lines follow roughly the same linear trend when it comes to production and energy consumption. The more the lines produce, the more energy they consume.

5.2. Model Validation. The authors started the model validation by looking at the real world data gathered from the case study company. In order to prove that the model is valid the authors sampled one month of actual data which included the production schedules for the three lines and the actual energy data. The authors compared side by side the production schedule and the actual energy data. This resulted in three main data streams: the first one contained the actual energy data for only the periods when the line was Running, the second one contained the actual energy data for only the periods when the line was in Market Downtime, and the third stream recorded the actual energy data for only the periods when the line was in shift cycle downtime. This process was repeated for each production line. At the end of this process the actual data was recorded in the Interface document.

The next step in the testing process involved running the simulation model five times. At the end of the simulation the results were exported in the Results document. This document reflects the average monthly energy consumption that was calculated for each of the production lines that are monitored by multiple energy meters. The authors decided to compare the monthly energy consumption generated from the simulation model for each meter as well as the overall energy consumption of each of the production lines with the actual production and energy data gathered from the case study company. This process was executed in a new document called Validation. This document contains the actual monthly energy data taken directly from company's PI and eSight systems, as well as the monthly data from the five runs of the simulation model. For greater accuracy the actual data was compared to the average data of the five simulation runs and the comparison was made based on common inputs of the production schedule.

Figures 11, 12, and 13 present graphs of the energy consumption data extrapolated from actual production processes compared with the average energy consumption data generated from the five simulation runs for Line 1, Line 2, and the finish line. The results indicate that the difference between the two sets of data (simulated versus actual) is not significant. For Line 1 the model is able to simulate the functionality and the energy consumption for this production line with an average accuracy of $96.53 \%$. This has been calculated by dividing the total average simulation run energy consumption for the 5 simulation runs to the total actual energy consumption for Line 1 . The margin of error within which the simulation model predicts the energy consumption for Line 1 is $-4.77 \%$ to $-2.71 \%$.

For Line 2 it can be seen from the associated graph that, apart from the Refiner Power, the rest of the simulated

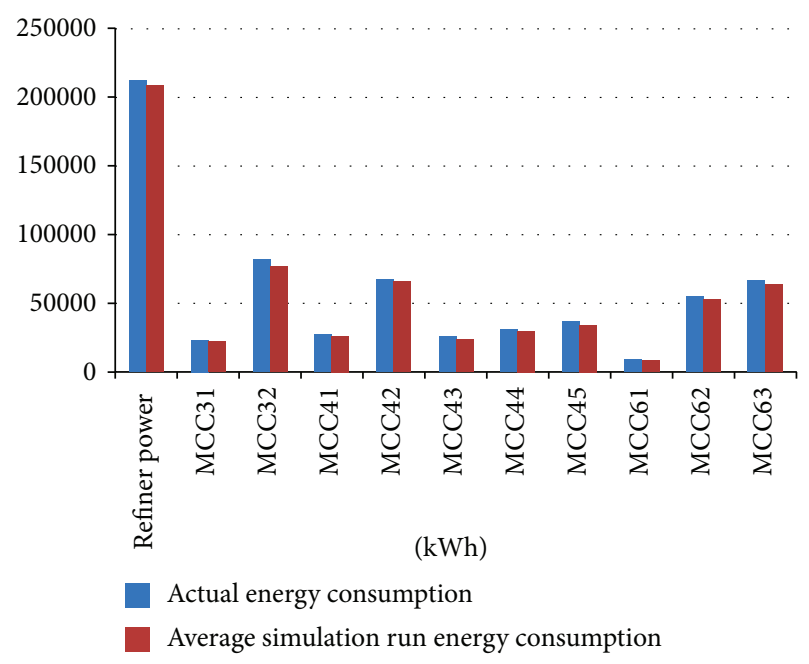

FIGURE 11: Line 1 energy data comparison between the actual data and the simulation results.

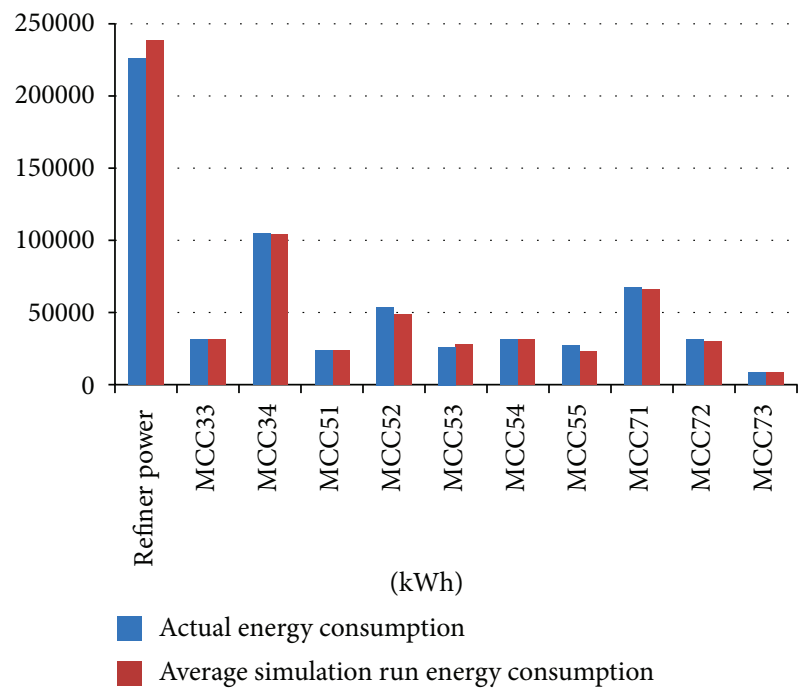

Figure 12: Line 2 energy data.

energy utilisation figures produced a very small difference when compared to the actual energy utilised within the production process. The results show the model is able to simulate the functionality and the energy consumption of production Line 2 with an average accuracy of $100.71 \%$. This result was obtained in the same manner as for line 1 , by dividing the total average simulation run energy consumption from the 5 model runs to the actual energy consumption for Line 2. The margin of error within which the model predicts the energy consumption of Line 2 is $-0.04 \%$ to $1.62 \%$.

The simulation model data for the finish line generated energy utilisation figures to an average accuracy of $94.94 \%$ when compared with actual energy utilisation figures for the line. The average accuracy figure was calculated in the same way as for Line 1 and Line 2 . The margin of error within which the simulation model predicts the energy consumption 
TABLE 3: Production data for the three main production lines.

\begin{tabular}{lccc}
\hline & Line 1 production units & Line 2 production units & Finish line production units \\
\hline $\begin{array}{l}\text { Actual totals } \\
\text { simulation totals }\end{array}$ & 11741 & 12391 & 643870 \\
Run 1 & 12144 & & 649120 \\
Run 2 & 12264 & 12969 & 639540 \\
Run 3 & 12085 & 12789 & 635040 \\
Run 4 & 12127 & 12214 & 663560 \\
Run 5 & 11880 & 12401 & 659690 \\
\hline Average & 12100 & 12565 & 649390 \\
Average/actual (\%) & $103.06 \%$ & 12588 & $100.86 \%$ \\
\hline
\end{tabular}

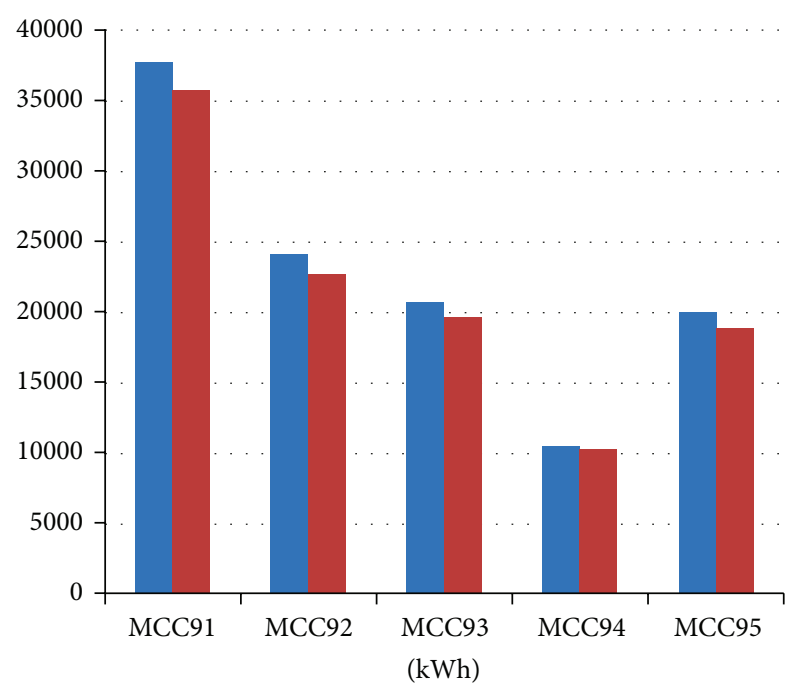

Actual energy consumption

Average simulation run energy consumption

FIGURE 13: Finish Line Energy Data.

of the finish line is $-5.71 \%$ to $-4.19 \%$. The margin of error for all three lines was calculated by analysing the five simulation runs, choosing the minimum and the maximum total energy value recorded between them and comparing it with the actual energy consumption recorded in the production process for the selected month. The margin of error is to be expected as the model uses probability distributions to simulate the production and energy consumption of the production processes associated with the 3 lines.

Table 3 presents the data collected from production processes as well as the data from the simulation model in terms of production volume. Column two presents the production data for Line 1, column three presents the production data for Line 2, and column four shows the production data for the Finish Line. The first row in this table looks at the actual data logged while the next rows look at the data logged in each of the five simulation runs for the three main production lines. The final two rows of the table record the average of the production data recorded in the five simulation runs as well as the percentage of the this average out of the actual
TABLE 4: The kWh/unit data for the three production lines.

\begin{tabular}{lccc}
\hline & Line 1 & Line 2 & Finish line \\
\hline Simulated & 3.61 & 3.60 & 0.17 \\
Actual & 3.85 & 3.63 & 0.18 \\
Simulated/actual\% & $93.67 \%$ & $99.14 \%$ & $95.32 \%$ \\
\hline
\end{tabular}

data recorded. This data shows the simulation model is able to predict the case company's production output within an average of $3.06 \%$ for Line $1,1.59 \%$ for Line 2 , and $0.86 \%$ for finish line.

For a better comparison with the real data the authors decided to calculate the amount of energy consumed for each HDF Units skin processed within the three production lines. In order to accomplish this, the total amount of energy consumed by each line has been divided by the total amount of HDF units produced by that line. The total amount of HDF' units produced by each line was obtained by multiplying the number of press loads by 14 , as there are 14 dies in the production press. The results can be found in Table 4 .

From Table 4 it can be determined that the accuracy of the simulation model in terms of kilowatt hours per unit (where 1 unit corresponds to $1 \mathrm{HDF}$ Unit) for Line 1 is $93.67 \%$, for Line 2 is $99.14 \%$, and for the finish line is $95.32 \%$. The authors, along with the production engineers from the case company, are satisfied that this is an acceptable margin of error as long as this data acts as a base for future variations of the model to be compared against. This would give a more realistic view of improvements made by future experiments conducted on the three production lines.

5.3. Conducted Scenarios Experiments. After the validation of the model the authors proceeded to implement a number of scenarios, which look at varying the model inputs to try to optimise the model outputs with the scope of lowering energy consumption and in the end lowering the kilowatthours per unit value for each line. The case company has also been involved in this process as they already have proposed a number of scenarios. They identified a number of projects they could implement to lower the energy consumption and decided to use the simulation model in order to prioritise between them. The first three experiments chosen to represent scenarios in the simulation model look at what 
TABLE 5: The data for the 10\% energy savings on the refiner scenario.

\begin{tabular}{lccc}
\hline & Line 1 & Line 2 & Line 1 + Line 2 \\
\hline Base simulation model & & & \\
Production (units) & 169,400 & 176,232 & 345,632 \\
Energy consumption (kWh) & 610,737 & 634,238 & $1,244,975$ \\
Cost $(€)$ & 366,442 & 380,543 & 746,985 \\
kWh/unit & 3.61 & 3.60 & 3.60 \\
$€ /$ unit & 2.16 & 2.16 & 2.16 \\
10\% energy savings on refiners & & & \\
scenario & & & \\
Production (units) & 169,400 & 176,232 & 345,632 \\
Energy consumption $(\mathrm{kWh})$ & 589,972 & 610,443 & $1,200,415$ \\
Cost (€) & 353,983 & 366,266 & 720,249 \\
kWh/unit & 3.48 & 3.46 & 3.47 \\
$€ /$ unit & 2.09 & 2.08 & 2.08 \\
Overall savings & & & \\
kWh saved/month & 20,765 & 23,795 & 44,560 \\
$€$ saved/month & 12,459 & 14,277 & 26,736 \\
kWh saved/year & 249,180 & 285,540 & 534,720 \\
$€$ saved/year & 149,508 & 171,324 & 320,832 \\
$\%$ kWh saved & $3.40 \%$ & $3.75 \%$ & $3.58 \%$ \\
$\%$ kWh/unit saved & $3.60 \%$ & $3.89 \%$ & $3.61 \%$ \\
$\% € /$ unit saved & $3.24 \%$ & $3.70 \%$ & $3.70 \%$ \\
\hline
\end{tabular}

the impact the reduction of energy consumption of the refiners and driers will have on the kilowatt hour per unit output and overall energy consumed. The following two scenarios look at lowering the press cycle time for both main production lines (Line 1 and Line 2) and how this impacts on production and energy consumption output in terms of kilowatt hour per unit. The last scenario looks at the impact that a change in the shift cycle might have on the production and energy consumption outputs. With this in mind the six chosen scenarios are as follows:

(i) $10 \%$ energy savings on refiners,

(ii) $10 \%$ energy savings on driers,

(iii) $15 \%$ energy savings on driers,

(iv) $3 \%$ press cycle time reduction,

(v) $8 \%$ press cycle time reduction,

(vi) 4-3-shift-cycle scenario.

The above scenarios have been implemented and run 5 times in order to determine a realistic average energy saving. The first scenario (Table 5) looked at the effects of lowering the refiners' energy consumption by $10 \%$ on the overall energy consumption and the kilowatt hours per unit. The companies production engineers are planning to achieve this target by redesigning the refiner plates and by making sure they maintain low energy consumption through changing used refiner plates sooner. This experiment resulted in an overall drop in energy consumption of the two main production lines by $3.58 \%$ which would save the case company approximately
$€ 320,800$ per year. This cost has been calculated with the following formula:

$$
\begin{aligned}
& \text { Cost }=((\text { L1 Base Energy Consummed } \\
&- \text { L1 Scenario Energy Consummed }) \\
&+(\text { L2 Base Energy Consummed } \\
&\quad-\text { L2 Scenario Energy Consummed })) \\
& * 12 * € 0.6 .
\end{aligned}
$$

Within the above formula,

(i) L1 base energy consumed represents the Line 1 energy consumption that resulted from the run of the base simulation model for a duration of one month,

(ii) L1 scenario energy consumed represents the Line 1 energy consumption that resulted from the run of the simulation model within the current scenario for a duration of one month,

(iii) L2 base energy consumed represents the Line 2 energy consumption that resulted from the run of the base simulation model for a duration of one month,

(iv) L2 scenario energy consumed represents the Line 2 energy consumption that resulted from the run of the simulation model within the current scenario for a duration of one month,

(v) 12 represents the number of months in order to find the approximate cost per year,

(vi) 0.6 represents the approximation in euro, of the cost of one $\mathrm{kW}$ of energy consumed at the time of this study; this figure has been provided by the production engineers as the approximate figure that they are using within their estimations of the cost of energy consumption.

In terms of $\mathrm{kWh} /$ unit the implementation of this scenario would decrease the amount of $\mathrm{kWh} /$ unit by $3.60 \%$ for Line 1 and by $3.89 \%$ for Line 2 . As the refiner performance does not affect the finish line, this has been left out of the calculations. In terms of cost, the implementation of this scenario would decrease the amount of $€$ /unit by $3.24 \%$ for Line 1 and $3.70 \%$ for Line 2.

The second and third scenarios looked at the effects of lowering the energy consumption of the driers by $10 \%$ and by $15 \%$. This can be achievable by analysing the design of the driers and reducing airflows through the system where possible. Typically, during the design of the dryers, the designers build in safety margins. This design will then be taken by a production engineer who will add his own safety margins. This results in large safety margins that cause waste of energy. When the $10 \%$ energy savings on driers scenario were run, the overall results showed a decrease of only $1.62 \%$ in the energy consumption for Line 1 and $2.15 \%$ for Line 2. This was translated in a total of approximately $€ 170,000$ savings per year. This can be calculated by using the cost formula presented in Table 3 and the data in the 
TABLE 6: The kWh/unit data for the 15\% energy savings on the driers scenario.

\begin{tabular}{|c|c|c|c|c|c|c|}
\hline & Line $1(10 \%)$ & Line $2(10 \%)$ & Line $1+$ Line $2(10 \%)$ & Line $1(15 \%)$ & Line $2(15 \%)$ & Line $1+$ Line $2(15 \%)$ \\
\hline \multicolumn{7}{|l|}{ Base simulation model } \\
\hline Production (units) & 169,400 & 176,232 & 345,632 & 169,400 & 176,232 & 345,632 \\
\hline Energy consumption (kWh) & 610,737 & 634,238 & $1,244,975$ & 610,737 & 634,238 & $1,244,975$ \\
\hline Cost $(€)$ & 366,442 & 380,543 & 746,985 & 366,442 & 380,543 & 746,985 \\
\hline $\mathrm{kWh} /$ unit & 3.61 & 3.60 & 3.60 & 3.61 & 3.60 & 3.60 \\
\hline$€ /$ unit & 2.16 & 2.16 & 2.16 & 2.16 & 2.16 & 2.16 \\
\hline \multicolumn{7}{|l|}{ Scenarios simulation data } \\
\hline Production (units) & 169,400 & 176,232 & 345,632 & 169,400 & 176,232 & 345,632 \\
\hline Energy consumption (kWh) & 600,838 & 620,579 & $1,221,417$ & 595,887 & 613,721 & $1,209,608$ \\
\hline Cost $(€)$ & 360,502 & 372,347 & 732,849 & 357,532 & 368,232 & 725,764 \\
\hline $\mathrm{kWh} /$ unit & 3.54 & 3.52 & 3.53 & 3.52 & 3.48 & 3.50 \\
\hline$€ /$ unit & 2.13 & 2.11 & 2.12 & 2.11 & 2.09 & 2.10 \\
\hline \multicolumn{7}{|l|}{ Overall savings } \\
\hline kWh saved/month & 9,899 & 13,659 & 23,558 & 14,850 & 20,517 & 35,367 \\
\hline$€$ saved/month & 5,940 & 8,196 & 14,136 & 8,910 & 12,311 & 21,221 \\
\hline kWh saved/year & 118,788 & 163,908 & 282,696 & 178,200 & 246,204 & 424,404 \\
\hline$€$ saved/year & 71,280 & 98,352 & 169,632 & 106,920 & 147,732 & 254,652 \\
\hline \% kWh saved & & $2.15 \%$ & $1.89 \%$ & $2.43 \%$ & $3.23 \%$ & $2.84 \%$ \\
\hline$\% \mathrm{kWh} /$ unit saved & $1.94 \%$ & $2.22 \%$ & $1.94 \%$ & $2.49 \%$ & $3.33 \%$ & $2.77 \%$ \\
\hline$\% € /$ unit saved & $1.39 \%$ & $2.31 \%$ & $1.85 \%$ & $2.31 \%$ & $3.24 \%$ & $2.77 \%$ \\
\hline
\end{tabular}

Table 6 , by adding the Line 1 and Line $2 €$ saved/month and multiplying this sum by 12 . In terms of the amount of energy consumed for each HDF Unit produced, the implementation of this scenario resulted in a $1.94 \%$ decrease in the amount of $\mathrm{kWh}$ /unit for Line 1 and $2.22 \%$ decrease for Line 2. Apart from this, the implementation of this scenario would decrease the cost per unit by $1.39 \%$ for Line 1 and $2.31 \%$ for Line 2 .

The $15 \%$ energy savings on the driers scenario also resulted in fairly low energy savings of $2.43 \%$ for Line 1 and $3.23 \%$ for Line 2 . By using the cost formula, as previously detailed, the cost of these energy savings can be calculated at approximately $€ 254.000$ per year, or $2.31 \%$ of cost savings for each unit produced by Line 1 and $3.24 \%$ cost savings per unit produced by Line 2 . This scenario also decreased the amount of $\mathrm{kW} / \mathrm{unit}$ by $2.49 \%$ for Line 1 and $3.33 \%$ for Line 2 as it can be seen in Table 6 .

The next two scenarios looked at the press cycle time for the main two production lines. The case company wanted to consider lowering the press cycle times associated with these lines by $3 \%$ and $8 \%$ respectively. The simulation model provided a better understanding of the impact the implementation of these two projects could have on the amount of $\mathrm{kWh} /$ unit consumed. The fourth considered scenario is the lowering of the press cycle of both production lines to $3 \%$. This resulted in a reduction of energy consumption for Line 1 from $610,737 \mathrm{kWh}$ per month to $607,175 \mathrm{kWh}$ per month which represents a $0.58 \%$ decrease in energy consumption. For Line 2 the monthly energy consumption dropped from $634238 \mathrm{kWh}$ to $632,014 \mathrm{kWh}$ which represents a $0.35 \%$ decrease in energy consumption. The overall decrease in energy consumption for the two lines would save the case company approximately $€ 40,000$ per year. This cost is calculated from the data presented in Table 7 by adding the Line 1 and Line $2 €$ saved/month and multiplying this sum by 12 . Apart from this saving an increase in production can be noticed: from 169,400 units to 175,784 units for Line 1, which represents a $3.77 \%$ increase and from 176,232 units to 182,938 units for Line 2, which represents a $3.80 \%$ increase. This implies a decrease of the $\mathrm{kWh} /$ unit by $4.43 \%$ for Line 1 and $4.17 \%$ for Line 2 (Table 7 ).

The next scenario considered was the ideal $8 \%$ press cycle time reduction for both of the production lines. This resulted in a decrease in energy consumption form $610,737 \mathrm{kWh}$ to $603,403 \mathrm{kWh}$ for Line 1, which represents a decrease of $1.20 \%$ and from $634,238 \mathrm{kWh}$ to $627,577 \mathrm{kWh}$ for Line 2, which represents a decrease of $1.05 \%$. This would save the case company approximately $€ 100,700$ per year, cost calculated by adding the $€$ saved/month for both Line 1 and Line 2 and multiplying the result by 12 . Similarly to the previous scenario an increase in production was noticed from 169,400 units to 184,212 units for Line 1, which represents an $8.74 \%$ increase and from 176,232 units to 192,052 units for Line 2, which represents an $8.98 \%$ increase. This decreased the $\mathrm{kWh} / \mathrm{unit}$ value by $9.41 \%$ for Line 1 and $9.44 \%$ for Line 2 . This was found to be the most productive scenario encountered and the data can be found in Table 8 .

The final scenario considered was the change in the production cycle from 10-4 to $4-3$, meaning that, instead of 10 days running and 4 days shift cycle downtime, the factory would be running 4-day with 3 night shift cycle downtime. After running the scenario five times, the authors compared the average results to the base line simulation results. Table 8 
TABLE 7: The data for the $3 \%$ press cycle time reduction scenario.

\begin{tabular}{|c|c|c|c|}
\hline & Line 1 & Line 2 & Line $1+$ Line 2 \\
\hline \multicolumn{4}{|c|}{ Base simulation model (base press cycle time (100\%)) } \\
\hline Production (units) & 169,400 & 176,232 & 345,632 \\
\hline Energy consumption (kWh) & 610,737 & 634,238 & $1,244,975$ \\
\hline Cost $(€)$ & 366,442 & 380,543 & 746,985 \\
\hline $\mathrm{kWh} /$ unit & 3.61 & 3.60 & 3.60 \\
\hline$€ /$ unit & 2.16 & 2.16 & 2.16 \\
\hline \multicolumn{4}{|l|}{$3 \%$ press cycle time reduction } \\
\hline Production (units) & 175,784 & 182,938 & 358,722 \\
\hline Energy consumption $(\mathrm{kWh})$ & 607,175 & 632,014 & $1,239,189$ \\
\hline Cost $(€)$ & 364,305 & 379,208 & 743,513 \\
\hline kWh/unit & 3.45 & 3.45 & 3.45 \\
\hline$€ /$ unit & 2.07 & 2.07 & 2.07 \\
\hline \multicolumn{4}{|l|}{ Overall savings } \\
\hline kWh saved/month & 3,562 & 2,224 & 5,786 \\
\hline$€$ saved/month & 2,137 & 1,335 & 3,472 \\
\hline $\mathrm{kWh}$ saved/year & 42,744 & 26,688 & 69,432 \\
\hline$€$ saved/year & 25,644 & 16,020 & 41,664 \\
\hline$\% \mathrm{kWh}$ saved & $0.58 \%$ & $0.35 \%$ & $0.46 \%$ \\
\hline$\% \mathrm{kWh} /$ unit saved & $4.43 \%$ & $4.17 \%$ & $4.17 \%$ \\
\hline$\% € /$ unit saved & $4.17 \%$ & $4.17 \%$ & $4.17 \%$ \\
\hline
\end{tabular}

TABLE 8: The data for the $8 \%$ press cycle time reduction scenario.

\begin{tabular}{lccc}
\hline & Line 1 & Line 2 & Line 1+ Line 2 \\
\hline Base simulation model & & & \\
Production (units) & 169,400 & 176,232 & 345,632 \\
Energy consumption (kWh) & 610,737 & 634,238 & $1,244,975$ \\
Cost $(€)$ & 366,442 & 380,543 & 746,985 \\
kWh/unit & 3.61 & 3.60 & 3.60 \\
$€ /$ unit & 2.16 & 2.16 & 2.16 \\
$8 \%$ press cycle time reduction & & & \\
Production (units) & 184,212 & 192,052 & 376,264 \\
Energy consumption $(\mathrm{kWh})$ & 603,403 & 627,577 & $1,230,980$ \\
Cost (€) & 362,041 & 376,546 & 738,588 \\
$\mathrm{kWh} /$ unit & 3.27 & 3.26 & 3.26 \\
$€ /$ unit & 1.96 & 1.96 & 1.96 \\
Overall savings & & & \\
$\mathrm{kWh}$ saved/month & 7,334 & 6,661 & 13,995 \\
$€$ saved/month & 4,401 & 3,997 & 8,398 \\
$\mathrm{kWh}$ saved/year & 88,008 & 79,932 & 167,940 \\
$€$ saved/year & 52,812 & 47,964 & 100,776 \\
$\% \mathrm{kWh}$ saved & $1.20 \%$ & $1.05 \%$ & $1.12 \%$ \\
\% kWh/unit saved & $9.41 \%$ & $9.44 \%$ & $9.44 \%$ \\
$\% € /$ unit saved & $9.26 \%$ & $9.26 \%$ & $9.26 \%$ \\
\hline
\end{tabular}

shows the results in detail. In the case of the 4-3 shift cycle scenario the energy consumption for each line changed is as follows: (i) from $610,737 \mathrm{kWh}$ to $633,720 \mathrm{kWh}$ for Line 1 , which represents an increase in energy consumption of $3.95 \%$,

(ii) from $634,238 \mathrm{kWh}$ to $623,672 \mathrm{kWh}$ for Line 2 , which represents a decrease in energy consumption by $1.83 \%$,

(iii) from $107,227 \mathrm{kWh}$ to $107,643 \mathrm{kWh}$ for finish line, which represents an increase in energy consumption of $0.4 \%$.

In terms of $\mathrm{kWh} /$ unit the implementation of this scenario would result in

(i) $0.27 \%$ decrease in $\mathrm{kWh} / \mathrm{unit}$ for Line 1 ,

(ii) no change for Line 2 ,

(iii) $6.25 \%$ decrease in $\mathrm{kWh} / \mathrm{unit}$ in the case of finish line.

The results also show that the case company would pay approximately $€ 92,000$ more per year on energy consumption. This cost has been calculated by adding the amounts listed in the $€$ saved/month row from Table 9 and multiplying the result by 12 . At the same time the cost/unit would decrease by $0.46 \%$ for Line 1 and $10 \%$ for finish line, remaining the same for Line 2. This is possible because of the production increase from 169,400 units to 176,094 units for Line 1 and from 648,702 units to 673,174 units for finish line.

\section{Conclusions and Recommendations}

The validation process looked at one month of actual data collected from the case company. The testing and validation process resulted in a stream of data that represented a baseline 
TABLE 9: The data for the 4-3 shift cycle scenario compared to the 10-4 shift cycle scenario.

\begin{tabular}{|c|c|c|c|c|c|c|}
\hline & \multicolumn{3}{|c|}{ 10-4 shift cycle (base line) } & \multicolumn{3}{|c|}{ 4-3 shift cycle scenario } \\
\hline & Line 1 & Line 2 & Finish line & Line 1 & Line 2 & Finish line \\
\hline Production (units) & 169,400 & 176,232 & 648,702 & 176,094 & 173,005 & 673,174 \\
\hline Energy consumption (kWh) & 610,737 & 634,238 & 107,227 & 633,720 & 623,672 & 107,643 \\
\hline Cost $(€)$ & 366,442 & 380,543 & 64,336 & 380,232 & 374,203 & 64,585 \\
\hline kWh/unit & 3.61 & 3.60 & 0.16 & 3.60 & 3.60 & 0.15 \\
\hline$€ /$ unit & 2.16 & 2.16 & 0.10 & 2.15 & 2.16 & 0.09 \\
\hline \multicolumn{7}{|l|}{ Overall savings } \\
\hline kWh saved/month & & & & $-6,694$ & 3,227 & -416 \\
\hline$€$ saved/month & & & & $-13,790$ & 6,340 & -249 \\
\hline$\%$ Energy saved & & & & $-3.95 \%$ & $1.83 \%$ & $-0.4 \%$ \\
\hline$\% \mathrm{kWh} /$ unit saved & & & & $0.27 \%$ & $0 \%$ & $6.25 \%$ \\
\hline$\% € /$ unit saved & & & & $0.46 \%$ & $0 \%$ & $10 \%$ \\
\hline
\end{tabular}

TABLE 10: The data collected from the 6 scenarios simulated.

\begin{tabular}{lcccc}
\hline ID & Scenario & $\mathrm{kWh} /$ Unit & Energy consumption & Approximate savings/year \\
\hline 1 & $10 \%$ energy savings on refiners & $3.74 \%$ & $3.58 \%$ & $€ 320,800$ \\
2 & $10 \%$ energy savings on driers & $2.08 \%$ & $1.89 \%$ & $€ 170,000$ \\
3 & $15 \%$ energy savings on driers & $2.91 \%$ & $2.84 \%$ & $€ 254,000$ \\
4 & $3 \%$ press cycle time reduction & $4.30 \%$ & $0.46 \%$ & $€ 40,000$ \\
5 & $8 \%$ press cycle time reduction & $9.42 \%$ & $1.12 \%$ & $€ 100,700$ \\
6 & $4-3$ shift cycle scenario & $3.14 \%$ & $-0.84 \%$ & $€-92,000$ \\
\hline & Maximum total & $25.59 \%$ & $9.05 \%$ & $€ 675,500$ \\
\hline
\end{tabular}

for further experiments and scenarios implemented on the simulation model. The following six scenarios were then considered to implement, with the scope of lowering the amount of energy consumed for each HDF unit produced (kWh/Unit):

(i) $10 \%$ energy savings on refiners,

(ii) $10 \%$ energy savings on driers,

(iii) $15 \%$ energy savings on driers,

(iv) $3 \%$ press cycle time reduction,

(v) $8 \%$ press cycle time reduction,

(vi) 4-3 shift cycle scenario.

After the six scenarios were implemented within the model and the simulation was run five times for the period of one month, the data was collected and analysed. Table 10 presents all the data gathered from the 6 scenarios.

After running all the scenarios and analysing the data presented above it can be quantified that the case company could save up to $€ 675,500$ per year if they were to implement the best-case scenarios: scenario 1 , scenario 3 , and scenario 5. Scenario 2 and scenario 3 are mutually exclusive as well as scenario 4 and scenario 5. However the authors recommended the implementation of scenario 4 or 5 , which assume a decrease in the cycle time of the two main production lines presses by $3 \%$ and $8 \%$, respectively. Even though this does not result in a major reduction in energy consumption, it represents a substantial boost in productivity, which increases the savings in $\mathrm{kWh} / \mathrm{Unit}$ to up to $9.44 \%$. This means the case company would consume almost the same amount of energy but produce almost $10 \%$ more HDF units. Another scenario that should not be disregarded is the $10 \%$ decrease in energy consumption on the refiners. This would bring the energy consumption as well as the $\mathrm{kWh} /$ Unit down by over $3.5 \%$ which would save the company approximately $€ 320,800$ per year. The authors consider that the scenarios mentioned above can be seen as the best ones to implement in terms of long-term investment with a steady return for the case company.

The HDF process simulation model developed for this research can be further developed to cover other forms of energy consumption. This would require further research in the area of thermal energy consumption as well as production management, which was outside the scope of this research. The primary role of the developed simulation model was to help the case company understand the implications of the different scenarios they would like to implement on the actual production system and to provide them with some insights around the returns that those scenarios could bring. The following are some recommendations for future work in this area.

(i) This model was developed for a HDF manufacturing company. The same modelling and development approach can also be applied to other manufacturing 
processes which rely on highly automated processes with sufficient data for modelling.

(ii) Although the model already implements most of the case company's processes, it is limited to the three production lines which consume the most electrical energy. As a future implementation the model could include the representation of the entire factory operation to include all production processes. This will allow for a better understanding of the entire manufacturing system and may uncover different implications of the implemented scenarios.

(iii) A further development of the simulation model could also include the modelling of thermal energy (heat and steam). This could have a great impact on identifying where expended thermal energy output from critical production resources may be captured and reused. It should also investigate multiple closed loop scenarios that could be deployed to convert captured energy back into electrical energy that could be reutilised.

(iv) The current simulation model does not take into account the case company's supply chain. The authors recommend a future development to include the implementation of the supply chain management as well as distribution management systems within the simulation model. This could assist the case company to make decisions regarding their needs for raw material, inventory levels, and production schedules. If the company can simulate the demand, it would be able to adapt its production schedule to suit it. This could result in major savings in energy consumption.

(v) The simulation model could also facilitate the user with cost reports. At the moment all the cost calculations are done in the excel document where the results are exported. At the same time these cost calculations represent an approximation of real energy costs and do not keep track of the difference between day and night or summer and winter tariffs. This could be a major addition to the simulation model as the costs could be implemented to keep track of different energy prices at different times of the day/year. This will provide the case company with an extra level of accuracy that will assist in the decision-making process regarding production schedules.

(vi) A final addition to the simulation software could be the implementation of an alternative energy source, such as a wind turbine or solar panels. The simulation of these resources could help the case company realise the return on a major investment like this and also facilitate the decision making process by backing it up with simulation data.

\section{Conflict of Interests}

The authors declare that there is no conflict of interests regarding the publication of this paper.

\section{References}

[1] Y. Seow and S. Rahimifard, "A framework for modelling energy consumption within manufacturing systems," CIRP Journal of Manufacturing Science and Technology, vol. 4, no. 3, pp. 258264, 2011.

[2] S. Thiede, Y. Seow, J. Andersson, and B. Johansson, "Environmental aspects in manufacturing system modelling and simulation-state of the art and research perspectives," CIRP Journal of Manufacturing Science and Technology, vol. 6, no. 1, pp. 78-87, 2013.

[3] J. R. Duflou, J. W. Sutherland, D. Dornfeld et al., “Towards energy and resource efficient manufacturing: a processes and systems approach," CIRP Annals-Manufacturing Technology, vol. 61, no. 2, pp. 587-609, 2012.

[4] M. Schipper, "Energy-related carbon dioxide emissions in U.S. manufacturing," U.S. Energy Information Administration DOE/EIA-0573, 2005, http://www.eia.doe.gov/oiaf/1605/ggrpt/ pdf/industry_mecs.pdf.

[5] DECC, "Industrial energy consumption in the UK between 1970 and 2013," in Energy Consumption in the United Kingdom 2014, chapter 4, 2014, https://www.gov.uk/government/uploads/ system/uploads/attachment_data/file/337456/ecuk_chapter_4_ industrial_factsheet.pdf.

[6] A. Gontarz, J. Plehn, A. Sproedt, L. Weiss, and K. Wegener, "Resource consumption measurement in manufacturing environments," in Proceedings of the 10th Global Conference for Sustainable Manufacturing, 2012.

[7] N. Diaz-Elsayed, A. Jondral, S. Greinacher, D. Dornfeld, and G. Lanza, "Assessment of lean and green strategies by simulation of manufacturing systems in discrete production environments," CIRP Annals-Manufacturing Technology, vol. 62, no. 1, pp. 475-478, 2013.

[8] N. Diaz and D. Dornfeld, "Cost and energy consumption optimization of product manufacture in a flexible manufacturing system," in Leveraging Technology for a Sustainable World: Proceedings of the 19th CIRP Conference on Life Cycle Engineering, University of California at Berkeley, Berkeley, USA, May 23-25, 2012, pp. 411-416, Springer, Berlin, Germany, 2012.

[9] A. Negahban and J. S. Smith, "Simulation for manufacturing system design and operation: literature review and analysis," Journal of Manufacturing Systems, vol. 33, no. 2, pp. 241-261, 2014.

[10] J. Kohl, S. Spreng, and J. Franke, "Discrete event simulation of individual energy consumption for product-varieties," Procedia CIRP, vol. 17, pp. 517-522, 2014.

[11] C. Herrmann, S. Thiede, S. Kara, and J. Hesselbach, "Energy oriented simulation of manufacturing systems-concept and application," CIRP Annals_Manufacturing Technology, vol. 60, no. 1, pp. 45-48, 2011.

[12] J. Li and S. Pang, "Modelling of energy demand in an MDF plant," in Proceedings of the CHEMECA: Knowledge and Innovation Conference, Auckland, New Zealand, September 2006.

[13] L. M. H. Carvalho, M. R. N. Costa, and C. A. V. Costa, "A global model for the hot-pressing of MDF," Wood Science and Technology, vol. 37, no. 3-4, pp. 241-258, 2003.

[14] L. Jingge, P. Shusheng, and E. W. Scharpf, "Modeling of thermal energy demand in MDF production," Forest Products Journal, vol. 57, no. 9, pp. 97-104, 2007.

[15] S. Robinson, Simulation: The Practice of Model Development and Use, John Wiley \& Sons, New York, NY, USA, 2004. 
[16] T. M. Maloney, “The family of wood composite materials," Forest Products Journal, vol. 46, no. 2, pp. 19-26, 2006.

[17] T. W. Tewoldeberhan, A. Verbraeck, E. Valentin, and G. Bardonnet, "An evaluation and selection methodology for discreteevent simulation software," in Proceedings of the Winter Simulation Conference, E. Yücesan, J. L. Snowdon, and J. M. Charnes, Eds., vol. 1, pp. 67-75, Piscataway, NJ, USA, 2002.

[18] J. Swain, "Discrete-event simulation software tools explore strange new worlds and re-examine ones we thought we knew," OR/MS Today, vol. 36, 2007.

[19] J. Swain, "Simulation software survey," OR/MS Today, vol. 36, 2009.

[20] OSIsoft, http://www.osisoft.com/.

[21] eSightenergy, http://www.esightenergy.com/.

[22] ProModel, http://www.promodel.com. 

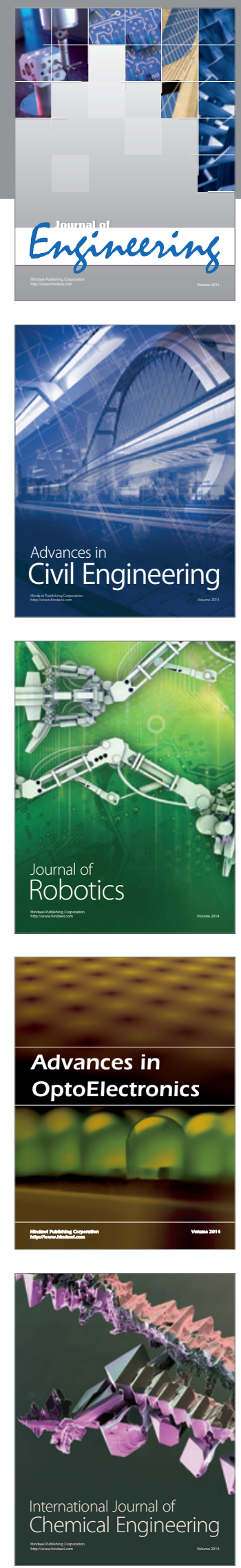

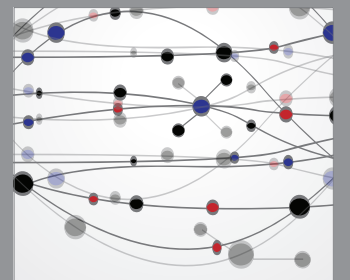

The Scientific World Journal
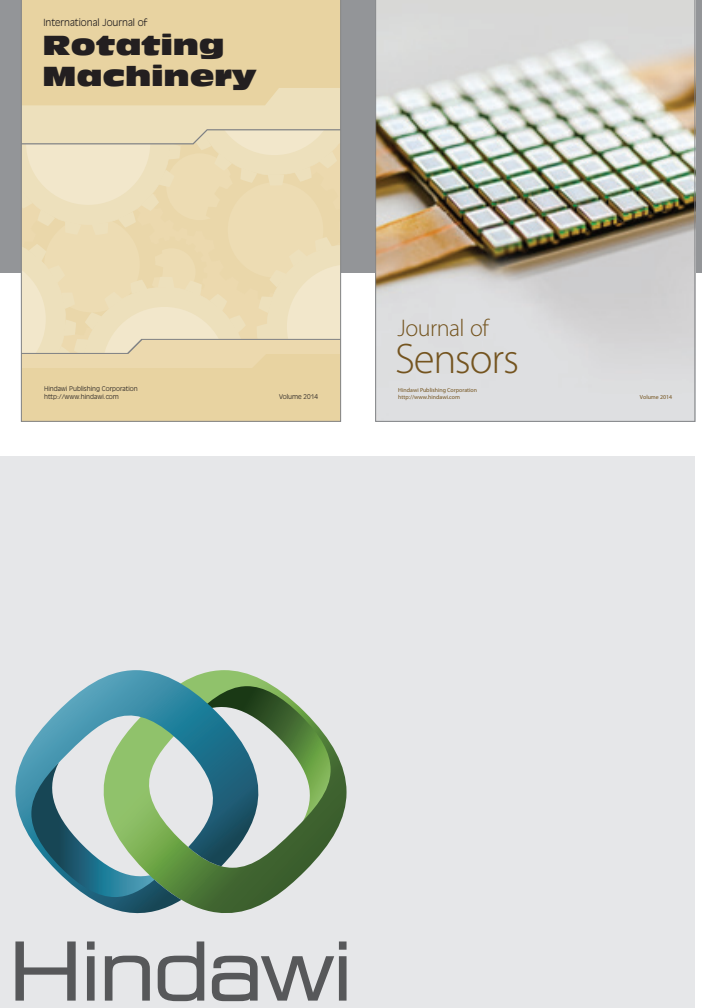

Submit your manuscripts at http://www.hindawi.com
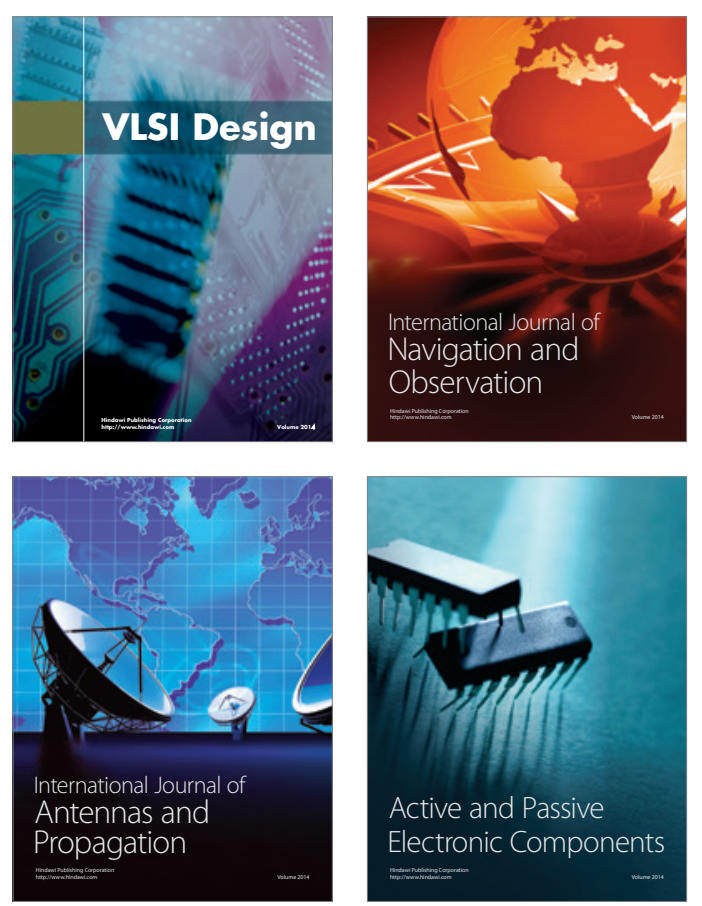
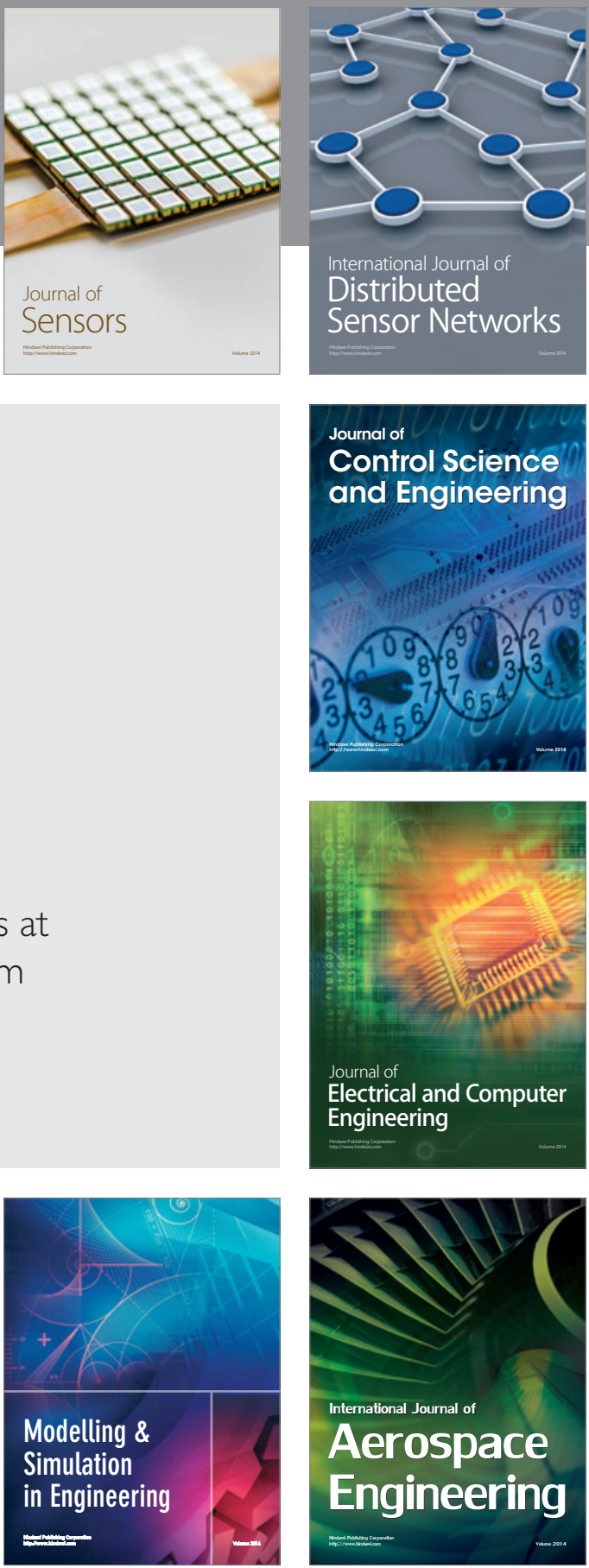

Journal of

Control Science

and Engineering
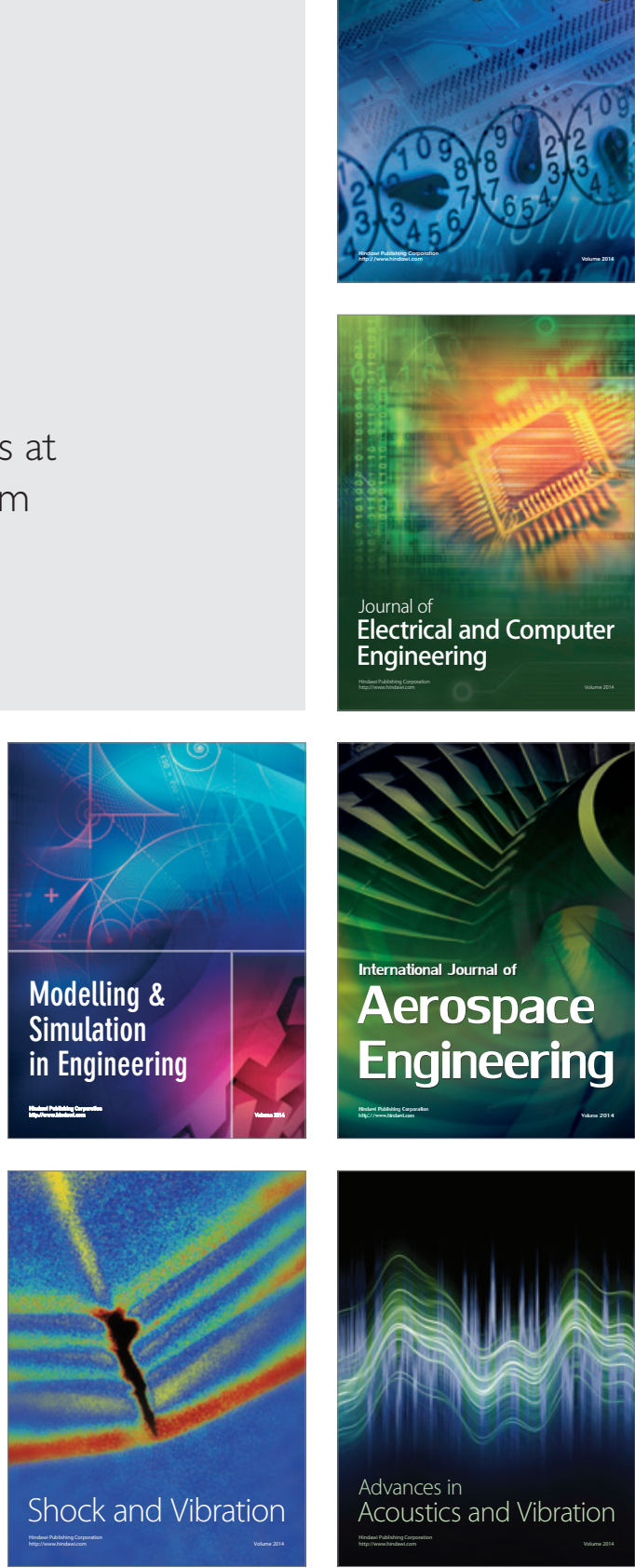